\title{
Environmental effects of tourism and its seasonality on Mediterranean islands: the contribution of the Interreg MED BLUEISLANDS project to build up an approach towards sustainable tourism
}

\author{
Cristina Andolina ${ }^{1,2} \cdot$ Geraldina Signa $^{1,2} \mathbb{D} \cdot$ Agostino Tomasello $^{1} \cdot$ Antonio Mazzola $^{1,2}$. \\ Salvatrice Vizzini ${ }^{1,2}$
}

Received: 4 June 2020 / Accepted: 12 September 2020 / Published online: 18 September 2020

(C) The Author(s) 2020

\begin{abstract}
The Mediterranean basin is amongst the world's main tourist destination, and its islands are a major attraction, being sites of historical, cultural and naturalistic importance. This is beneficial for the local economies, but it may also represent a great burden on the coastal environment, where other human pressures are concentrated. The awareness of detrimental side effects of tourism together with the importance to take into account social and economic facets has led to the concept of sustainable tourism, which, however, represents a goal far from being attained. A good opportunity to promote sustainable tourism was provided by the Interreg MED BLUEISLANDS project, whose main aim was to identify, address and mitigate the effects of the seasonal variation of waste generated by tourism on Mediterranean islands. Here, we present the methodological framework of the project aimed at biomonitoring coastal seawater in highly touristic sites using macroalgae as valuable bioindicators of seawater quality and improving its status through the implementation and assessment of mitigation measures that included also the involvement of stakeholders. Outcomes of the project highlighted the effectiveness of such an integrated approach, confirming the importance of choosing proper indicators and tools that can support the development of management plans aiming to mitigate environmental impact and foster sustainable tourism.
\end{abstract}

Keywords Sustainability $\cdot$ Coastal management $\cdot$ Waste $\cdot$ Mitigation $\cdot$ Stakeholders · Microalgae $\cdot$ Bioindicator

Geraldina Signa

geraldina.signa@unipa.it

1 DiSTeM, Dipartimento di Scienze della Terra e del Mare, Università degli Studi di Palermo, via Archirafi, 18, Palermo, Italy

2 CoNISMa, Consorzio Nazionale Interuniversitario per le Scienze del Mare, Rome, Italy 


\section{Introduction}

Islands are generally considered unique destinations to spend peaceful and idyllic holidays. The natural potential of the islands as " $3 \mathrm{~S}$ " destination (sun, sand and sea), viewed as the exact opposite to urbanized life, represents the foundation of the boom of mass tourism that interested many islands since the middle of the last century (Carlsen and Butler 2011). In particular, the impressive cultural heritage, coupled with the richness of natural sceneries and the mild climate, make Mediterranean islands among the major tourist destinations worldwide, substantially contributing to a great economic growth (Apostolopoulos and Gayle 2002). However, tourism cannot be viewed simply as an economic activity, having a great influence on socio-cultural and environmental aspects, especially in the islands where the intrinsic "insularity" leads to a multitude of constraints. Isolation, small spatial extent, limited resources and fragile ecosystems are among the main constraints that magnify the effects of tourism and make difficult the formulation of tourism management and development plans in the islands (Ioannides et al. 2001).

Mass tourism, intended as massive fluxes of tourists concentrated in small areas and short periods, is particularly associated to serious environmental impacts, including landuse conversion to respond to the high demand for accommodation and amenities, overexploitation of natural resources, poor waste management, and habitat loss and degradation due to overcrowding and tourism-associated pollution (Davenport and Davenport 2006; Hall 2001). Therefore, uncontrolled tourism development and unsustainable tourist flows may compromise the ecosystem services that coastal environments provide leading to negative repercussions to tourism itself (Drius et al. 2019). Environmental deterioration is one of the most common causes of tourists' disappointment and drives the choice of holiday destination (Torres-Bejarano et al. 2018). Consequently, today many islands are dealing with the lowering of tourism fluxes because of the deterioration of the natural environment (Dodds and Graci 2012).

Although the need to implement sustainable practices for reducing the environmental impact of tourism and ensuring its long-term success has been invoked since the last 30 years (Inskeep 1991), it is still a widely debated issue at both scientific and government level (Mihalic 2016) lacking a common systematic effort. Important steps ahead have been recently done, as sustainability in the tourism sector has been recently included in the agendas of many international agencies (i.e. UN, UNDP, UNEP, UNESCO, UNWTO) (Cooper et al. 2018).

Indeed, in the 2030 Agenda for Sustainable Development (UN 2015), sustainable tourism is considered one of the tools to achieve multiple Sustainable Development Goals (SDG), covering from economy (SDG 8) to responsible consumption (SDG 12) to the marine environment (SDG 14). Similarly, sustainable coastal and maritime tourism is one of the 5 priorities of the EU Blue Growth Strategy (EU Commission 2017). Although the assessment of the tourism impact is among the main goals defined by the UN and EU strategies, scientific-based approaches, such as environmental impact assessment and environmental monitoring, are scant or severely constrained by time and funding, hence resulting of low scientific quality (Davenport and Davenport 2006). This is often coupled by low awareness and promotion of good practices for proper resource use and waste management. Within this framework, the Mediterranean Strategy for Sustainable Development MSSD (UNEP/MAP 2016) represents an important step towards the harmonization of socio-economic and environmental issues, promoting also regional cooperation in support of sustainable development in the Mediterranean area. 
Consistently with the MSSD, the European Interreg MED Programme supports innovative projects for the enhancement of sustainability in the Mediterranean area. In this context, the Interreg MED BLUEISLANDS project (https://blueislands.interreg-med. $\mathrm{eu} /$ ) aimed to improve the knowledge about tourism-driven waste, build common guidelines and support synergies among Mediterranean islands, to accomplish sustainable tourism patterns and promote circular economy in the Mediterranean area. In more detail, the BLUEISLANDS project gathered 14 partners from eight European countries in order to properly identify, address and mitigate the effects of the seasonal variation of waste production as an effect of tourist flows, based on an integrated scientific and socio-economic approach. Among the other aims, the BLUEISLANDS project represented a good opportunity to explore the relationship between coastal tourism and anthropogenic nutrient enrichment in coastal seawater of highly tourism destinations in three Mediterranean islands: Cyprus, Sicily (Italy) and Rhodes (Greece). Anthropogenic nutrients can arise from land, e.g. sewage outfalls, septic tanks or inadequate sewage systems at resorts, and may cause the worsening of coastal seawater quality and deterioration of marine habitats facing tourist beaches, which may, consequently, lose their aesthetic value and their functionality of recreation spots (Botero et al. 2015).

The purposes of the project, with reference to the issue of anthropogenic nutrients enrichment in coastal seawater in tourist sites, were achieved through a precise methodology that defined the actions to be implemented. In particular, the project was structured into 3 phases: the "Studying phase", to investigate the seasonal variation of anthropogenic nutrients in seawater using biological indicators; the "Testing phase" to propose solutions addressing the problem of seasonal variation of anthropogenic nutrients due to tourism, through the implementation and the assessment of a series of pilot activities; the "Transferring phase" to facilitate the exchange of knowledge among the project partners and external stakeholders.

Here, we aim to describe the processes, tools and methods adopted within the framework of the Interreg MED BLUEISLANDS project to biomonitor anthropogenic nutrients in coastal seawater of highly touristic sites at 3 Mediterranean islands (Cyprus, Sicily and Rhodes) and to improve seawater status through the implementation of pilot activities that actively involved stakeholders.

\section{Methodology and results: the case study of three Mediterranean islands}

The first step to set out the project activities consisted in the identification of the study islands, in agreement with the project partners. The islands of Cyprus, Sicily and Rhodes were selected being very popular tourist destinations in the Mediterranean area, with a well-defined seasonality of demographic fluxes concentrated in small coastal towns and with an appropriate logistics for the implementation of the activities. Three popular coastal tourist beaches, Protaras (Cyprus), Giardini Naxos (Sicily) and Faliraki (Rhodes), characterized by a high density of tourist facilities and small local businesses were selected as study sites in the three islands. In particular, the HORECA sector was exhaustively represented in all the 3 sites, with plenty of hotels, resorts, restaurants, cafes and kiosks both at beachfront at the back of the beaches. Moreover, a number of recreational activities, lidos, beach games and sport pitches, floating walkways and playgrounds, water sports and watercraft, characterized the chosen beaches. 


\subsection{Studying phase}

In order to gather the background information on the relationship between tourism seasonality and changes in seawater quality in the study sites, an experimental approach based on the ability of biological indicators to track spatial and temporal variation in anthropogenic nutrients was adopted. The use of biological indicators, namely organisms that undergo detectable variations in their natural status in presence of environmental alteration, is one of the most effective methods to evaluate and follow over time changes in the quality of the environment (Burger 2006). Therefore, in this study marine macroalgae were used as bioindicators, due to the high assimilation rates of nutrients present in the water column (Hurd et al. 2014). In particular, active biomonitoring experiments were carried out, based on the short-term transplantation of macroalgae from pristine donor sites to tourist sites to allow them to take up the nutrients available in the recipient seawater and record in their tissues the possible occurrence of anthropogenic nutrients (García-Seoane et al. 2018). A large body of literature showed that macroalgae are suitable bioindicators to track several types of anthropogenic input into coastal systems (e.g. sewage outflow, agriculture runoff, aquaculture effluents) at different spatial scales (up to a few $\mathrm{km}$ ) from the input sources (e.g. Amato et al. 2016; Costanzo et al. 2001; García-Sanz et al. 2011).

A detailed description of the experimental procedures implemented in the studying phase is available in Signa et al. (2020b). Briefly, the biomonitoring campaigns were conducted in 2017 in Cyprus and Sicily and in 2018 in Rhodes, after agreeing with the Local Authorities the formal procedures to carry out the experiments while limiting any interferences with bathing and boating activities. The biomonitoring campaigns were conducted in three periods of the year, June, August and October, respectively, before, during and after the summer tourist peak, and in 3 sites, the tourist site and 2 reference sites characterized by the absence of tourist facilities. In the 3 sites, three species of intertidal macroalgae belonging to the genus Cystoseira, namely $C$. humilis in Cyprus, C. amentacea var. stricta in Sicily and C. compressa in Rhodes (Fig. 1) were collected from a donor site and transplanted for 3 days within removable devices installed in a grid of equidistant georeferenced points distributed along three transects at 100, 200 and $300 \mathrm{~m}$ distance from the coastline (at 200, 250 and $300 \mathrm{~m}$ in Sicily only). The accuracy of the distance from the coastline was of $10 \mathrm{~m}$ according to the handheld personal navigator used (GPS12, Garmin).

(a) C. humilis
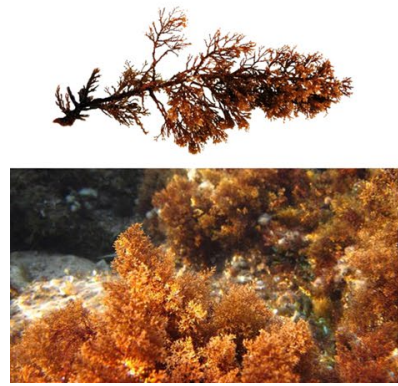

(b) C. amentacea
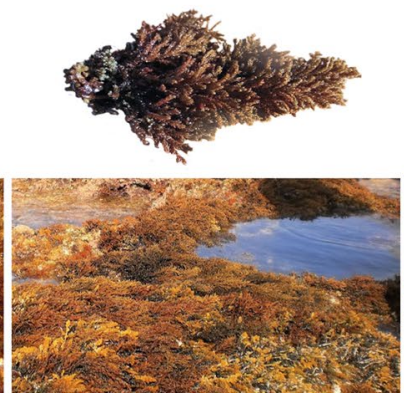

(c) C. compressa
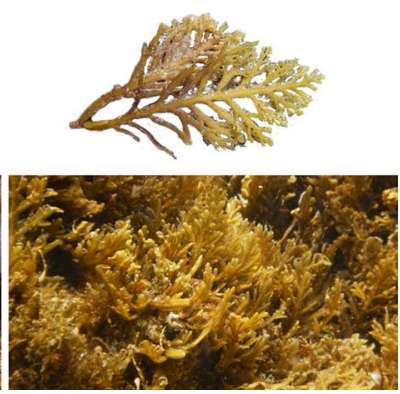

Fig. 1 The three species of macroalgae belonging to the genus Cystoseira used in the experiments a $C$. humilis used in Cyprus; b C. amentacea var. stricta used in Sicily; c C. compressa used in Rhodes. Individual fronds and the natural settings of the three macroalgae are showed above and below, respectively 
Then the macroalgae were analysed for the ratio of the stable isotopes of nitrogen (expressed as $\delta^{15} \mathrm{~N} \%$ ), which gives indication of the origin of the nutrients assimilated (e.g. Cole et al. 2005; Fernandes et al. 2012; Mancinelli and Vizzini 2015; Mwaura et al. 2017; Signa et al. 2012). The results were used to calculate the change in $\delta^{15} \mathrm{~N}\left(\Delta \delta^{15} \mathrm{~N}\right)$, as the difference of $\delta^{15} \mathrm{~N}$ values recorded at the beginning and at the end of the experiment, and that indicates the extent of the enrichment in anthropogenic nutrients in the coastal water. Three levels of enrichments were established: $\Delta \delta^{15} \mathrm{~N}<0.5 \%$; $0.5<\Delta \delta^{15} \mathrm{~N}<1.0 \%$; $\Delta \delta^{15} \mathrm{~N}>1.0 \%$ o that indicated, respectively, a low, moderate or high occurrence of anthropogenic nutrients in seawater.

The results obtained were summarized in easily readable outputs useful to be consulted by project partners during the decisional process aimed at defining the follow-up mitigation measures. For this purpose, the georeferenced data collected during the biomonitoring were interpolated in GIS maps, in which different colour contours indicate the different levels of the change in $\delta^{15} \mathrm{~N}\left(\Delta \delta^{15} \mathrm{~N}\right)$ recorded by macroalgae at the end of the transplant period. As an example, the GIS map elaborated for the tourist site of Cyprus (Fig. 2) indicates a moderate isotopic enrichment in the landward transect in June and October, which then increases and spreads up to the offshore transect in August (Signa et al. 2020b). Despite these results revealed a general moderate influence of anthropogenic activities on nutrient presence in coastal seawater, the spatial pattern seemed strictly associated to coastal inputs, thereby the relationship found with tourism seasonality suggested that specific strategies are needed to be proposed and adopted in order to further limit the presence of anthropogenic nutrients in the study sites investigated.

\subsection{Testing phase}

The main aim of the testing phase of the project was to overcome and mitigate the seasonal variation of anthropogenic nutrients into the coastal waters of the study islands due to tourism, through the planning, implementation and assessment of pilot activities.

Pilot activities were defined based on the results of the biomonitoring campaigns carried out during the studying phase. In particular, although no dramatic extent but
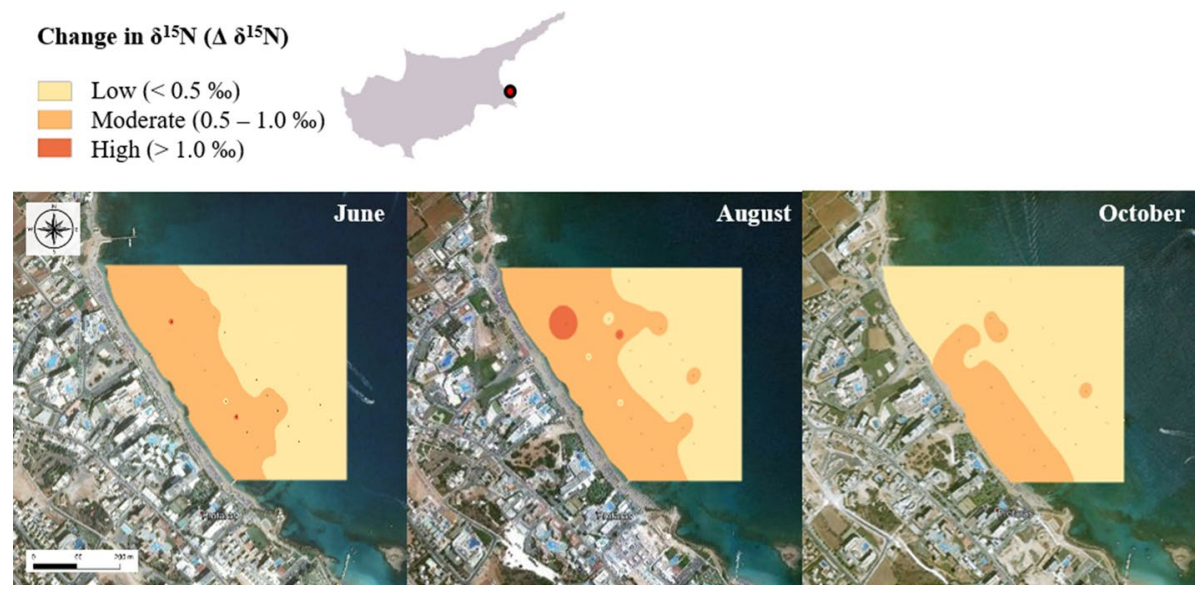

Fig. 2 GIS maps of the change in $\delta^{15} \mathrm{~N}\left(\Delta \delta^{15} \mathrm{~N}\right)$ at the tourist site of Cyprus in June, August and October 2017. Maps are taken from Signa et al. (2020b) 
only a low to moderate anthropogenic enrichment was detected in coastal seawater of the three islands (see Signa et al. 2020b for more details), the findings of the studying phase were used as the main inputs for a decision support tool specifically developed to orient strategic and operational decisions depending on the different site-specific characteristics. In this way, the local partners of the three islands set a protocol of specific objectives and a description of the activities to be implemented.

There was a general consensus that pilot activities had to be centred on raising awareness of many stakeholders, from the beach users to the hotel managers, using also a variety of media available, about the environmental effects of tourism. Therefore, an awareness-raising campaign was conducted in summer (mainly August) 2019 in the same tourist sites where the biomonitoring was previously carried out. Several on-site dissemination events were conducted by setting information points at the beaches, where local project partners carried out the awareness campaign by (1) informing both tourists and local people not only about the project aims and activities but in general about the effects on the environment that stem from tourism practices, (2) fostering a correct behaviour of tourists (proper waste disposal, waste recycling, reduction in the input of organic matter into the sea), (3) promoting good practices in the field of sustainable tourism. Moreover, by conveying simple and clear messages, tourists were also informed about the importance of efficient wastewater management to avoid unpleasant deterioration of seawater, and about the threats and impacts of litter to coastal marine ecosystems and marine life. Furthermore, informative posters and leaflets about these issues were placed and distributed at the beaches, resorts, beach kiosks, diving centres and tourist offices. Beachgoers were also awarded of small gifts such as recyclable bags, reusable bamboo straws and cups, carton ashtrays for smokers, to discourage the use of single-use items. Websites of local newspapers were used to inform online users about the project activities going on in the islands, as well as social media and radio adverts disseminated environmental awareness messages. Finally, new bins for recycling and non-recyclable wastes were placed, and waste collections points and toilets were properly signalled.

The effectiveness of the pilot activities on the reduction in anthropogenic nutrients in coastal seawater was assessed by repeating, in August 2019, the same biomonitoring campaign carried out in 2017 (2018 in Rhodes; see Signa et al. 2020b for more details) during the studying phase and by comparing the results before and after the implementation of the pilot activities. In more detail, the transplant experiment was performed again in the tourist sites of the 3 islands and the frequency of the change in $\delta^{15} \mathrm{~N}\left(\Delta \delta^{15} \mathrm{~N}\right)$ data falling into the three predefined classes was compared between the 2 campaigns. The threshold value of $80 \%$ of $\Delta \delta^{15} \mathrm{~N}$ data falling into the category low was considered the target to reach for considering successful the pilot activities implemented. An example of the frequency of $\Delta \delta^{15} \mathrm{~N}$ data elaborated for the tourist site of Cyprus is reported in Fig. 3. Despite the target was not reached in Cyprus, the frequency of $\Delta \delta^{15} \mathrm{~N}$ data falling in the category of $\delta^{15} \mathrm{~N}$ enrichment of the transplanted macroalgae "Low" increased from 56\% in 2017 to $75 \%$ in 2019 after the pilot activities implementation. Overall, the results of the assessment phase highlighted the effectiveness of the pilot activities in all the islands: although the target was reached only in 2 out of 3 islands, a substantial improvement was always evident by comparing the frequency of the change in $\delta^{15} \mathrm{~N}\left(\Delta \delta^{15} \mathrm{~N}\right)$ data recorded in the 2 campaigns, respectively, before and after the implementation of the pilot activities. 
Fig. 3 Comparison of the frequency of the change in $\delta^{15} \mathrm{~N}$ $\left(\Delta \delta^{15} \mathrm{~N}\right)$ data indicating 'Low', 'Moderate' and 'High' presence of anthropogenic nutrients in coastal seawater of the Tourist site of Cyprus, as resulted from the biomonitoring campaigns carried out during the study phase (2017) and the testing phase of the project (2019). The threshold of the target to be reached in 2019 is also indicated

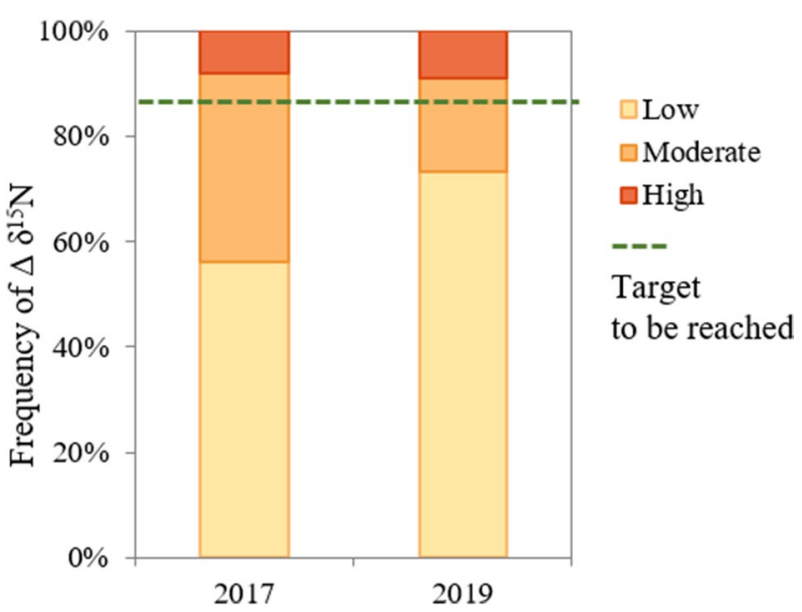

\subsection{Transferring phase}

The last phase of the project was specifically focused on a wide range of capitalization and dissemination activities by bringing the knowledge obtained throughout the project to as many people as possible. The main targets were operators of the tourism sector, local and international policy-makers and environmental managers.

\section{Discussion}

Reduction in the environmental impacts of tourism and the maintenance of the carrying capacity of tourist destinations are key challenges today within the framework of sustainable tourism (UNEP/MAP 2016 and sustainable development. This is particularly urgent in the Mediterranean area, given its environmental vulnerability (Coll et al. 2012), together with its leading position in the world tourism sector (Piante and Ody 2015), and especially in its islands, given their strong dependence on tourism and their limited opportunities to differentiate economic activities (Albers and Baldachinno 2017). Nevertheless, the approaches mostly used to assess the tourism-driven social and environmental degradation are the analysis of the carrying capacity of tourist sites and users' perception questionnaire-based surveys (Gonson et al. 2018), both often lacking a strong scientific base (Davenport and Davenport 2006).

Here, we described the scientific-based approach that has been applied in the framework of the Interreg Med BLUEISLANDS project and that falls within one of the main challenges of the European Interreg Programme, which is "to study, test and capitalize innovative tools and actions towards the enhancement of tourism sustainability in the Mediterranean" (https://sustainable-tourism.interreg-med.eu/). Overall, the 3-step methodology applied within the BLUEISLANDS project was fruitful to accomplish the project's goals, namely the development of effective approaches and tools to monitor and mitigate the adverse environmental effects resulting from the seasonal variation of waste in Mediterranean islands in relation to the touristic flows. 
During the first phase of the project (i.e. the studying phase), the manipulative experiments that were carried out in highly touristic sites of Cyprus, Sicily and Rhodes based on short-term microalgae transplantation, allowed to highlight temporal variation in the occurrence of nutrients of anthropogenic origin in coastal seawater. Results were carefully analysed, mapped and compared among periods, and showed that the increase in tourists during the peak season (i.e. summer) was associated with an increase in anthropogenic nutrients in coastal seawater (Signa et al. 2020b). The increase in anthropogenic nutrients may arise from sewage discharge into coastal waters due to the population rise during the high season and/or recreational and bathing activities (Signa et al. 2020b), but the method adopted did not allow to discern the contribution of these two potential sources of nutrients. However, the main strength of the approach used arises from the effectiveness of the chosen indicators (macroalgae and nitrogen stable isotopes) to detect the origin of nutrients in coastal seawater (e.g. Costanzo et al. 2001; Viana et al. 2011; García-Seoane et al. 2018), combined with the ability of GIS maps in summarizing data in a simple and easily readable way. Good indicators should be able, indeed, to track trends over space and time in response to stressors (Burger 2006), and, at the same time, they should be efficient in communicating the meaning of the highlighted trends to stakeholders with various interests and backgrounds (e.g. policymakers, scientists, the general public and the media).

A plethora of sustainable tourism indicators and indices have been developed so far to monitor through time and inform about the level of sustainability of many tourist destinations, but most of them focus on socio-cultural and political sustainability rather than environmental sustainability (Mihalic 2016; Torres-Delgado and Saarinen 2014 and references therein). Great attention is paid, indeed, to the use of energy by air transport in the calculation of the ecological footprint, which is considered a valuable environmental indicator of sustainable tourism (Gössling et al. 2002; Hunter and Shaw 2007). In contrast, although the quality of bathing water is a key element for tourists, and hence one of the major resources to be safeguarded in tourist destinations (Lucrezi and van der Walt 2016), it is rarely considered in the development of tourism indicators. For instance, the research carried out by Blancas et al. (2010) in Spain is one of the few cases in which a set of environmental indicators centred on waste management and beach use and condition was used to evaluate the tourism sustainability of coastal destinations. Among these, the percentage of beach area with Blue Flag status was used in the study. The Blue flag prize is one of the world's most diffused eco-labels awarded to beaches, according to a series of stringent environmental, educational, safety, and accessibility criteria, among which seawater quality is one of the pillars and is based on the analysis of microbiological and physical-chemical variables.

Following the studying phase, the strategic and innovative decision tool designed to set the operational decisions to be carried out according to the different site-specific characteristics, allowed to plan the follow-up pilot activities to be implemented in the islands and to set the target to be reached through the pilot activity implementation. By this point, the site-specific pilot activities implemented by the project partners constituted the basis for the testing phase, while the following assessment step constituted the practical testing phase of the project, as the obtained results, in terms of fulfilment of the established targets, highlighted the effectiveness of the measures implemented in the mitigation process. This phase was characterized by the involvement of various types of stakeholders, to raise their awareness on the environmental impact of tourism and promoting sustainable choices. In particular: (1) a network with HORECA and tourist stakeholders (e.g. managers and employers of diving centres, lidos and tourist offices) was created as they were directly 
involved in the pilot activities implementation; (2) tourists were reached during the implementation of the pilot activities in the high tourist sites, where they were informed about the site-specific environmental issues and their active role in making a difference; there is a general consensus about the efficacy of engaging an open dialogue with people for promoting best practices making them feel an active part of the solution (Diamantis 2000; Mihalic 2016). Therefore, activities like direct speaking to beachgoers and dissemination of informative posters at the entrance of the main local services were effective in delivering the message of sustainable use of the tourist site; (3) policy-makers and competent authorities were informed about the results of the 2-year monitoring of seawater depending on tourist flows; proactive proposals through the definition of guidelines for the development of action plans that minimize the negative effects of tourism on the coastal ecosystems and encourage the establishment of good practices and circular economies for sustainable tourism were made.

Moreover, throughout the project duration, and especially in the transferring phase, the project partners organized many events focusing on the relationship between waste management, environmental impact and tourism. All these events were a great opportunity to meet many other stakeholders, offering great visibility to the BLUEISLANDS project, the related goals, the activities implemented and the results achieved. This is certainly another positive aspect of the project, as effective communication and collaboration among stakeholders are crucial to building up a strategy to foster sustainable tourism, which indeed embraces the environment, social and political aspects, as well as the broader context of sustainable development (Gabarda-Mallorquí et al. 2016; Zolfani et al. 2015).

Lastly, the BLUEISLANDS project represented a big challenge and opportunity for scientists and stakeholders to have a proactive dialogue about issues (i.e. the seasonality of waste generation due to tourism in the Mediterranean area) rarely addressed on such wide scale before. Indeed, although there are places where the tourism sector exerted strong pressures on the public administrations to ensure optimal bathing water quality by properly managing the wastewater treatment processes (Gabarda-Mallorquí et al. 2016), in most cases, poor or inefficient wastewater management during the high peak season is still a critical issue to be addressed.

\section{Conclusion}

Sustainable tourism in Mediterranean islands is an important driver needed to requalify the tourist offer in response to a growing international demand for sustainability, while preserving the natural heritage, communities and ecosystems. The long-term success of tourism depends on the maintenance of the appeal of tourist destinations and user satisfaction, which, in turns, depends on good environmental quality. Therefore, it is increasingly evident the urgent need for a holistic approach that embraces both environmental, economic and social aspects in support of tourism policies focused on monitoring and mitigation measures based on scientific evidence, innovative approaches and strong synergies between the scientific community and tourism stakeholders. The Interreg Med BLUEISLANDS project follows this direction, moving from the classical monitoring approaches toward an integrated approach based on the application of scientific-based indicators and the implementation of mitigation measures. This is consistent with the Mediterranean Strategy for Sustainable Development (UNEP/MAP 2016), which highlights the importance of the involvement of the scientific community and the development of analytical 
tools able to assess and forecast tourism-related impacts in support of policymakers. Main project findings showed a low to moderate influence of anthropogenic activities in the tourist sites studied and an overall improvement of the seawater quality throughout the project, confirming the importance of raising public awareness on environmental issues and how a direct dialogue with stakeholders allows to positively influence their behaviour. Such an approach that combines the reliability of the scientific approach with the direct involvement of interested parties had the potential to be highly successful in accelerating policy changes towards the development of effective management of sustainable tourism.

Acknowledgements This work was supported by the Interreg Mediterranean-European Regional Development Fund (BLUEISLANDS project: Seasonal variation of waste as effect of tourism. Ref: 613/1MED15_3.1_M12_273). No potential conflict of interest was reported by the authors. We are grateful to all the project partners and, in particular, to the Department of Environment of the Ministry of Agriculture, Rural Development and Environment of Cyprus, the Taormina Etna Consortium and the Municipality of Rhodes. We are also grateful to all the LaBioMar (University of Palermo) staff for the field and laboratory support.

Funding Open access funding provided by Università degli Studi di Palermo within the CRUI-CARE Agreement.

Open Access This article is licensed under a Creative Commons Attribution 4.0 International License, which permits use, sharing, adaptation, distribution and reproduction in any medium or format, as long as you give appropriate credit to the original author(s) and the source, provide a link to the Creative Commons licence, and indicate if changes were made. The images or other third party material in this article are included in the article's Creative Commons licence, unless indicated otherwise in a credit line to the material. If material is not included in the article's Creative Commons licence and your intended use is not permitted by statutory regulation or exceeds the permitted use, you will need to obtain permission directly from the copyright holder. To view a copy of this licence, visit http://creativecommons.org/licenses/by/4.0/.

\section{References}

Albers, A., \& Baldachinno, G. (2017). Resilience and tourism in Islands: Insights from the Caribbean. In R. W. Butler (Ed.), Tourism and resilience (pp. 150-162). Wallingford: CABI.

Amato, D. W., Bishop, J. M., Glenn, C. R., Dulai, H., \& Smith, C. M. (2016). Impact of submarine groundwater discharge on marine water quality and reef biota of Maui. PLOS ONE, 11(11), 1-28. https://doi. org/10.1371/journal.pone.0165825.

Apostolopoulos, Y., \& Gayle, D. J. (2002). Island tourism and sustainable development: Caribbean, Pacific, and Mediterranean experiences. Westport: Praeger.

Blancas, F. J., González, M., Lozano-Oyola, M., \& Pérez, F. (2010). The assessment of sustainable tourism: Application to Spanish coastal destinations. Ecological Indicators, 10(2), 484-492. https://doi. org/10.1016/j.ecolind.2009.08.001.

Botero, C., Pereira, C., Tosic, M., \& Manjarrez, G. (2015). Design of an index for monitoring the environmental quality of tourist beaches from a holistic approach. Ocean and Coastal Management, 108, 65-73. https://doi.org/10.1016/j.ocecoaman.2014.07.017.

Burger, J. (2006). Bioindicators: Types, development, and use in ecological assessment and research. Environmental Bioindicators, 1(1), 22-39. https://doi.org/10.1080/15555270590966483.

Carlsen, J., \& Butler, R. (2011). Introducing sustainable perspective of island tourism. In J. Carlsen \& R. Butler (Eds.), Island tourism: Towards a sustainable perspective (pp. 1-7). Wallingford: CABI.

Cole, M. L., Kroeger, K. D., McClelland, J. W., \& Valiela, I. (2005). Macrophytes as indicators of landderived wastewater: Application of a $\delta^{15} \mathrm{~N}$ method in aquatic systems. Water Resources Research, 41(1), 1-9. https://doi.org/10.1029/2004WR003269.

Coll, M., Piroddi, C., Albouy, C., Lasram, F. B. R., Cheung, W. W. L., Christensen, V., et al. (2012). The Mediterranean sea under siege: Spatial overlap between marine biodiversity, cumulative threats and marine reserves. Global Ecology and Biogeography, 21(4), 465-480. https://doi.org/10.111 1/j.1466-8238.2011.00697.x. 
Cooper, C., Volo, S., Gartner, W. C., \& Scott, N. (2018). The SAGE handbook of tourism management. London: SAGE Publications.

Costanzo, S. D., O’Donohue, M. J., Dennison, W. C., Loneragan, N. R., \& Thomas, M. (2001). A new approach for detecting and mapping sewage impacts. Marine pollution bulletin, 42(2), 149-156. https ://doi.org/10.1016/S0025-326X(00)00125-9.

Davenport, J., \& Davenport, J. L. (2006). The impact of tourism and personal leisure transport on coastal environments: A review. Estuarine, Coastal and Shelf Science, 67(1-2), 280-292. https://doi. org/10.1016/j.ecss.2005.11.026.

Diamantis, D. (2000). Ecotourism and sustainability in Mediterranean islands. Thunderbird International Business Review, 42(4), 427-443. https://doi.org/10.1002/1520-6874(20000 7/08)42:4<427::AID-TIE5>3.0.CO;2-G.

Dodds, R., \& Graci, S. (2012). Sustainable tourism in Island destinations. London: Earthscan.

Drius, M., Bongiorni, L., Depellegrin, D., Menegon, S., Pugnetti, A., \& Stifter, S. (2019). Tackling challenges for Mediterranean sustainable coastal tourism: An ecosystem service perspective. Science of the Total Environment, 652, 1302-1317. https://doi.org/10.1016/j.scitotenv.2018.10.121.

European Commission. (2017). Report on the blue growth strategy: Towards more sustainable growth and jobs in the blue economy. Commission staff working document on blue growth 2013-2016. Brussels.

Fernandes, M., Benger, S., Sharma, S. K., Gaylard, S., Kildea, T., Hoare, S., et al. (2012). The use of $\delta^{15} \mathrm{~N}$ signatures of translocated macroalgae to map coastal nutrient plumes: Improving species selection and spatial analysis of metropolitan datasets. Journal of Environmental Monitoring, 14, 2399-2410. https://doi.org/10.1039/c2em10997b.

Gabarda-Mallorquí, A., Fraguell, R. M., Pavón, D., \& Ribas, A. (2016). Tourist development and wastewater treatment in the Spanish Mediterranean coast: The Costa Brava case study. International Journal of Sustainable Development and Planning, 11(3), 245-254. https://doi.org/10.2495/ SDP-V11-N3-245-254.

García-Sanz, T., Ruiz, J. M., Pérez, M., \& Ruiz, M. (2011). Assessment of dissolved nutrients dispersal derived from offshore fish-farm using nitrogen stable isotope ratios $\left(\delta^{15} \mathrm{~N}\right)$ in macroalgal bioassays. Estuarine, Coastal and Shelf Science, 91(3), 361-370. https://doi.org/10.1016/j.ecss.2010.10.025.

García-Seoane, R., Fernández, J. A., Villares, R., \& Aboal, J. R. (2018). Use of macroalgae to biomonitor pollutants in coastal waters: Optimization of the methodology. Ecological Indicators, 84, 710-726. https://doi.org/10.1016/j.ecolind.2017.09.015.

Gonson, C., Pelletier, D., \& Alban, F. (2018). Social carrying capacity assessment from questionnaire and counts survey: Insights for recreational settings management in coastal areas. Marine Policy, 98, 146-157. https://doi.org/10.1016/j.marpol.2018.08.016.

Gössling, S., Borgström Hansson, C., Hörstmeier, O., \& Saggel, S. (2002). Ecological footprint analysis as a tool to assess tourism sustainability. Ecological Economics, 43(2-3), 199-211. https://doi. org/10.1016/S0921-8009(02)00211-2.

Hall, C. M. (2001). Trends in ocean and coastal tourism: The end of the last frontier? Ocean and Coastal Management, 44(9-10), 601-618. https://doi.org/10.1016/S0964-5691(01)00071-0.

Hunter, C., \& Shaw, J. (2007). The ecological footprint as a key indicator of sustainable tourism. Tourism Management, 28(1), 46-57. https://doi.org/10.1016/j.tourman.2005.07.016.

Hurd, C. L., Harrison, P. J., Bischof, K., \& Lobban, C. S. (2014). Seaweed ecology and physiology. Cambridge: Cambridge University press.

Inskeep, E. (1991). Tourism planning: An integrated and sustainable development approach. New York: Van Nostrand Reinhold.

Ioannides, D., Apostolopoulos, Y., \& Sönmez, S. (2001). Mediterranean islands and sustainable tourism development: Practices, management and policies. London: Pinter.

Lucrezi, S., \& van der Walt, M. F. (2016). Beachgoers' perceptions of sandy beach conditions: Demographic and attitudinal influences, and the implications for beach ecosystem management. Journal of Coastal Conservation, 20(1), 81-96. https://doi.org/10.1007/s11852-015-0419-3.

Mancinelli, G., \& Vizzini, S. (2015). Assessing anthropogenic pressures on coastal marine ecosystems using stable CNS isotopes: State of the art, knowledge gaps, and community-scale perspectives. Estuarine, Coastal and Shelf Science, 156(1), 195-204. https://doi.org/10.1016/j.ecss.2014.11.030.

Mihalic, T. (2016). Sustainable-responsible tourism discourse: Towards "responsustable" tourism. Journal of Cleaner Production, 111, 461-470. https://doi.org/10.1016/j.jclepro.2014.12.062.

Mwaura, J., Umezawa, Y., Nakamura, T., \& Kamau, J. (2017). Evidence of chronic anthropogenic nutrient within coastal lagoon reefs adjacent to urban and tourism centers, Kenya: A stable isotope approach. Marine Pollution Bulletin, 119(2), 74-86. https://doi.org/10.1016/j.marpolbul.2017.04.028. 
Piante, C., \& Ody, D. (2015). Blue growth in the Mediterranean sea: The challenge of good environmental status. WWF-France: Medtrends project.

Signa, G., Andolina, C., Mazzola, A., \& Vizzini, S. (2020a). Macroalgae transplant to detect the occurrence of anthropogenic nutrients in seawater of highly tourist beaches in Mediterranean islands. Ecological Questions, 31(4), 1-23. https://doi.org/10.12775/EQ.2020.030.

Signa, G., Andolina, C., Tomasello, A., Mazzola, A., \& Vizzini, S. (2020b). $\delta^{15} \mathrm{~N}$ in deployed macroalgae as a tool to monitor nutrient input driven by tourism activities in Mediterranean islands. Marine Pollution Bulletin. 159, 111504. https://doi.org/10.1016/j.marpolbul.2020.111504.

Signa, G., Mazzola, A., \& Vizzini, S. (2012). Effects of a small seagull colony on trophic status and primary production in a Mediterranean coastal system (Marinello ponds, Italy). Estuarine Coastal and Shelf Science, 111, 27-34. https://doi.org/10.1016/j.ecss.2012.06.008.

Torres-Bejarano, F., González-Márquez, L. C., Díaz-Solano, B., Torregroza-Espinosa, A. C., \& CanteroRodelo, R. (2018). Effects of beach tourists on bathing water and sand quality at Puerto Velero, Colombia. Environment, Development and Sustainability, 20(1), 255-269. https://doi.org/10.1007/ s10668-016-9880-x.

Torres-Delgado, A., \& Saarinen, J. (2014). Using indicators to assess sustainable tourism development: A review. Tourism Geographies, 16(1), 31-47. https://doi.org/10.1080/14616688.2013.867530.

UNEP/MAP. (2016). Mediterranean strategy for sustainable development 2016-2025. Valbonne: Plan Bleu, Regional Activity Centre Valbonne.

United Nations. (2015). Transforming our world: The 2030 agenda for sustainable development. General Assembly Resolution A/RES/70/1.

Viana, I. G., Fernández, J. A., Aboal, J. R., \& Carballeira, A. (2011). Measurement of $\delta^{15} \mathrm{~N}$ in macroalgae stored in an environmental specimen bank for regional scale monitoring of eutrophication in coastal areas. Ecological Indicators, 11(3), 888-895. https://doi.org/10.1016/j.ecolind.2010.12.004.

Zolfani, S. H., Sedaghat, M., Maknoon, R., \& Zavadskas, E. K. (2015). Sustainable tourism: A comprehensive literature review on frameworks and applications. Economic Research-Ekonomska Istrazivanja, 28(1), 1-30. https://doi.org/10.1080/1331677X.2014.995895.

Publisher's Note Springer Nature remains neutral with regard to jurisdictional claims in published maps and institutional affiliations. 